\title{
PI3K/Akt Pathway: A Potential Therapeutic Target for Chronic Pain
}

Running title: PI3K/Akt pathway: a potential therapeutic target for chronic pain

Authors: Shu-Ping Chen ${ }^{1,2}$, Ya-Qun Zhou ${ }^{1,2}$, Dai-Qiang Liu ${ }^{1,2}$, Wen Zhang ${ }^{1,2}$, Anne Manyande ${ }^{3}$, Xue-Hai Guan ${ }^{1,2}$, Yu-ke Tian ${ }^{1,2}$, Da-Wei Ye ${ }^{4}$, Deeq Mohamed Omar ${ }^{5}$

\section{Authors' affiliation:}

1. Anesthesiology Institute, Tongji Hospital, Tongji Medical College, Huazhong University of Science and Technology, Wuhan, China.

2. Department of Anesthesiology and Pain Medicine, Tongji Hospital, Tongji Medical College, Huazhong University of Science and Technology, Wuhan, China.

3. School of Human and Social Sciences, University of West London, Brentford, UK

4. Cancer Center, Tongji Hospital, Tongji Medical college, Huazhong University of Science and Technology, Wuhan, China.

5. MBBS, Tongji Medical College, Huazhong University of Science and Technology, Wuhan, China.

Corresponding author: Da-Wei Ye, MD, PhD, Cancer Center, Tongji Hospital, Tongji Medical college, Huazhong University of Science and Technology, Wuhan, China; e-mail: dy0711@ gmail.com; TEL: 00862783663409; FAX: 00862783662853

\begin{abstract}
Chronic pain is among the most disabling and costly disorders, with prevalence ranging from $10 \%$ to $55 \%$. However, current therapeutic strategies for chronic pain are unsatisfactory due to our poor understanding of its mechanisms. Thus, novel therapeutic targets need to be found in order to improve these patients' quality of life. PI3K and its downstream Akt are widely expressed in the spinal cord, particularly in the laminae I-IV of the dorsal horn, where nociceptive C and A $\delta$ fibers of primary afferents principally terminate. Recent studies have demonstrated their critical roles in the development and maintenance of chronic pain. In this review, we summarized the roles and mechanisms of PI3K/Akt pathway in the progression of chronic pain through sciatic nerve injury, diabetic neuropathy, spinal cord injury, bone cancer, opioid tolerance, or opioid-induced hyperalgesia.
\end{abstract}

Keywords: PI3K; Akt; chronic pain

\section{Introduction:}

Although physiological pain serves an important protective function, chronic pain can profoundly compromise the quality of life [1-3]. Chronic pain is divided into neuropathic pain, inflammatory pain and cancer pain[4]. Several studies have demonstrated that many pathological processes are characterized by chronic pain, such as sciatic nerve injury, human immunodeficiency virusassociated sensory neuropathy, diabetic neuropathy, spinal cord injury, bone cancer, opioid tolerance, and opioid-induced hyperalgesia. There are many features in chronic pain, including pain in response to normally innocuous stimuli (allodynia), an increased responsiveness to noxious stimuli 
(hyperalgesia) and pain experienced in the absence of any obvious peripheral stimulus (spontaneous pain)[5, 6]. The mechanism of chronic pain is extremely complicated including central sensitization and peripheral sensitization [2, 7-10].

Phosphoinositide 3-kinase (PI3K) has been demonstrated to be essential in the development and maintenance of chronic pain[11, 12]. It is a lipid kinase that phosphorylates the D3 position of the inositol ring of phosphoinositide and thereby generates intracellular signaling molecules such as phosphorylation of Akt (pAkt) at Thr308 and Ser473 [13]. The mammalian PI3K signaling family is categorized into three classes (I, II, III) according to their structure and substrate specificity [14, 15]. Class I isoforms have been most extensively studied. Class IA, which consists of PI3K $\alpha$, PI3K $\beta$ and PI3K $\delta$ isoforms, is often activated by hormones, cytokines, intergrin's, and growth factors via the tyrosine kinase receptors; while $\mathrm{PI} 3 \mathrm{~K} \gamma$ (the only member of class IB) is activated by G-proteincoupled receptors (GPCRs)[16-18]. It was demonstrated that the PI3K $\beta$ also can been coupled to GPCR [19]. PI3K $\delta$ and $\gamma$ are mainly expressed in the hematopoietic system and mediate immune responses, whereas $\mathrm{PI} 3 \mathrm{~K} \alpha$ and $\beta$ are ubiquitously expressed and regulate functions such as proliferation and survival. It is known that PI $3 \mathrm{~K} \gamma$ can also been found in endothelium[18], heart[17, 20] and brain[21]. Several lines of evidence have shown that activation of PI3K signaling is involved in the modulation of nociceptive information and central sensitization produced by intense noxious stimuli [22-24]. Importantly, PI3K has been reported to mediate central sensitization and hyperalgesia induced by activation of the central RTK system NGF/TrkA, BDNF/TrkB and GCSF/G-CSFR signaling[25]. Our previous studies revealed that PI3K mediates pain behaviors induced by the activation of peripheral ephrinBs/EphBs signaling in mice [26]. Besides, Akt plays an important role in diverse biological processes through phosphorylation on Thr308 and Ser473, as a key downstream substrate in the PI3K pathway[24]. It is also worth noting that systematic or spinal blocking PI3K with wortmannin or LY294002 prevents the mechanical and thermal hyperalgesia in a dose-dependent manner [27].

\section{PI3K/Akt Pathway and Bone Cancer Pain}

Bone cancer pain (BCP) is one of the most severe type of chronic pain [28-30]. It was reported that up to $85 \%$ of patients with advanced prostate, breast, and lung cancer had bone metastasis [31-33]. Moreover, one-third of these patients experienced unbearable pain, which severely affected their quality of life. It is now considered that BCP is mechanistically unique compared with neuropathic and inflammatory states [34-36]. In a rat model of BCP, we found that PI3K and its downstream target pAkt were up-regulated in a time-dependent manner and were required for the development and maintenance of BCP [37]. Additionally, PI3K is distributed mainly in the superficial layers of the spinal dorsal horn neurons, astrocytes and a minority of microglia [13, 37, 38]. PI3K pathway is activated by signals at the cell plasma membrane, such as IL-3, nerve growth factor, and insulinlike growth factor[39]. In the model of BCP, the MCP-1 activated the PLC- $\beta 2$, PI3K, ERK, p38, and Akt by binding to CCR2 [40]. In the central nervous system and peripheral nervous system, the activation of PI3K/Akt signaling pathway can mediate the mechanical and thermal hyperalgesia induced by nerve injury, incision, or inflammation[13, 41, 42]. There is growing evidence that $\mathrm{PI} 3 \mathrm{~K} / \mathrm{Akt}$ signaling pathway plays a critical role in regulating other signaling pathways, such as Raf/MEK/ERK pathway[43, 44], ephrin Bs/EphBs pathway[37], MAPK pathway[45], and MCP1/CCR2 pathway[46], which contribute to tumor genesis and cancer pain. For example, ERK signaling has been reported to contribute to synaptic and neuronal plasticity, and is involved in the 
modulation of peripheral and central sensitization induced by noxious stimuli and nociceptive information[47, 48]. It has been reported that activation of ephrinB2/EphB4 receptor signaling mediates micro vascular endothelial cell and retinal endothelial cell migration and proliferation via the PI3K/Akt pathway $[49,50]$. Then the microglia were activated, which contributed to the development of pain [46]. In a subset of prostate cancer cells, it has been demonstrated that Akt can positively regulate the Raf/MEK/ERK pathway at the level of B-Raf [44]. We have found that the activation of spinal chemokine receptor CXCR3 mediates bone cancer pain through an Akt-ERK crosstalk pathway [27]. A large body of evidence suggests that inhibition of PI3K attenuates the mechanical allodynia in BCP rats and can suppress BCP-associated behaviors [27, 51]. In the neural stem cells (NSCs), it has been demonstrated that fluoxetine can modulate the neuroprotection through up regulating expression of the phosphorylated-Akt and ERK1/2. Besides, expression of phosphorylated-Akt and phosphorylated-ERK1/2 in fluoxetine-treated NSCs was effectively blocked by both PI3K inhibitor (LY294002) and MEK inhibitor (PD98059) [43]. In the rats model of BCP, we have found that spinal or peripheral ephrinB1/EphB1 receptor signaling activated PI3K/Akt pathway, accompanied with thermal hyperalgesia and mechanical allodynia [26]. It has been demonstrated that the expression level of p-Akt co-expressed with OX-42 is increased, and decreased after inhibition by the PI3K inhibitor LY294002 in microglia. MCP-1 has been found to stimulate the PI3K/Akt pathway in some kinds of cells (monocytes, HEK-293, COS-7 and PC3)[52]. The PI3K/Akt signaling expressed in microglia could be activated by MCP-1, which lead to microglial activation and pain [46]. PI3K/Akt signaling pathway not only affect cancer pain, its dysregulation has also been involved in multiple pathological processes of tumor, including tumor genesis, invasion, proliferation, cell cycle progression, apoptosis and metastasis[53].

\section{PI3K/Akt Pathway and Neuropathic Pain}

Neuropathic pain is broadly defined as chronic pain that is initiated or caused by a primary lesion or dysfunction in the nervous system and may arise from a spectrum of traumatic insults to the nervous system [54-56]. An increasing number of studies have demonstrated that many factors can contribute to the development of neuropathic pain, such as inflammation [57], and changes in neurotransmission $[58,59]$. Neuropathic pain appears in many anomalous situations, including spinal cord injury[60], diabetes, peripheral nerve injury[61, 62] and in some inflammatory conditions $[24,41,63,64]$. A growing body of evidence has shown that activation of the PI3K/Akt pathway in the spinal cord contributes to hyperalgesia in many neuropathic models [46].

\section{PI3K/Akt Pathway and Sciatic Nerve Injury}

According to the previous studies, the rat model of partial sciatic nerve ligation (PSL) was designed to investigate peripheral neuropathic pain65, 66]. In this model, one group of rats were anesthetized and received a unilateral L5 sciatic nerve ligation; but in sham-operated rats, the left L5 spinal nerve was isolated, but without ligation [67].

Studies showed that the activation of PKA, PKC and MAPK signal pathway after peripheral nerve injury plays an important role in regulating the expression of sodium channel subtypes, and neuropeptides in DRG and contributes to the generation of pain-related behaviors[68, 69]. Furthermore, evidence shows that PI3K and Akt are crucial mediators that lead to the activation of the transcription factor nuclear factor $\mathrm{\kappa B}(\mathrm{NF}-\mathrm{\kappa B})$ induced by interleukin-1(IL-1) and tumor necrosis factor- $\alpha($ TNF- $\alpha)[70,71]$ which play a central role in the development of neuropathic 
pain[72]. It has been strained that neuroprotection is mediated via a TNFR2-PI3K-Akt-NF-kB pathway in which the duration of NF- $\mathrm{kB}$ activation is the critical determinant in mounting resistance toward excitotoxic insults. In accordance with the important role of NF-kB in neuroprotection, it has been demonstrated that upon in vitro glutamate exposure of TNF-treated cortical neurons, a PI3K-dependent Akt phosphorylation was ensued by NF-kB activation [71]. Several lines of evidence indicate that PI3K activation is the upstream of growth factor-induced Akt[73, 74] which is involved in pain hypersensitivity induced by intradermal injection of capsaicin in rats[75], so that PI3K can mediate pain behavior through the Akt signal pathway. In the PSL model, immunohistochemistry work shows that the p-Akt IR-positive neurons in ipsilateral L5 DRG and spinal cord significantly increased, but the significant change was not detected in the contralateral L5 spinal dorsal horn[64, 67]. To investigate the role of PI3K and Akt actvation in the development of neuropathic pain induced by L5 PSL, the PI3K inhibitor wortmannin or LY294002 as well as Akt specific inhibitor Akt inhibitor IV or (-)-Deguelin were injected intrathecally $30 \mathrm{~min}$ before surgery and once daily thereafter until the $7^{\text {th }}$ day after L5 PSL. Compared with the control group, in which rats received vehicle injection as above, wortmannin, LY294002, Akt inhibitor IV and (-)-Deguelin treatment significantly reduced mechanical allodynia and thermal hyperalgesia after L5 PSL on the $1^{\text {st }}$ day and $3^{\text {rd }}$ day, but not on the $7^{\text {th }}$ day [67]. In the model of paclitaxel-induced painful peripheral neuropathy, Akt inhibitor Mk-2206 at various doses (1,10 and $50 \mathrm{nmol})$ was intrathecally injected 30 min prior paclitaxel treatment for 10 consecutive days. Blocking of Akt1 activation with different inhibitor (MK-2206 or LY294002) attenuated mechanical allodynia and thermal hyperalgesia induced by paclitaxel [76]. The p-Akt is usually referred to as the marker of PI3K activation, which suggests that the PI3K and PI3K-Akt signal pathway might contribute to the development of neuropathic pain at an early stage.

\section{PI3K/Akt Pathway and Diabetic Neuropathy}

Diabetic neuropathy occurs in $25 \%$ of diabetic patients, and its mechanism remains largely unknown[77]. Diabetic neuropathy are characterized by a progressive loss of nerve fibers affecting both the autonomic and somatic divisions of the nervous system and only a minority are associated with pain[78]. Deficits in nerve growth factor (NGF) production and/or NGF transport in the target tissues of NGF-responsive neurons have been implicated in the pathogenesis of diabetic neuropathy[79, 80]. Previous work showed that a reduced retrograde axonal transport of NGF and neurotrophin-3 (NT-3) in the vagus nerve of diabetic rats occurred in the presence of normal production of neurotrophins and neurotrophin receptors[81]. Several lines of evidence have shown that the interaction between neurotrophins and the tyrosine kinase (Trk) receptor can activate the PI3K/Akt signal pathway which mediates neuron survival, differentiation, axon growth, and protects nerve regeneration[82, 83]. The PI3K/Akt signal pathway located in the distal axon of neurons has a unique role in the retrograde transport of NGF and brain-derived neurotrophic factor (BDNF) in sympathetic, sensory neurons and Moto neurons [84, 85]. Inhibition of PI3K in the distal axons attenuates the retrograde transport of NGF and also induces neuron apoptosis [86]. It has been reported that diabetes decreases the activity of the PI3K and Akt in the vagus nerve, without affecting the protein expression of the p85 subunit of PI3K, Akt and phosphorylation of Akt, but increases the phosphorylation of p70s6 kinase[87]. A growing body of evidence have demonstrated that peripheral noxious insults caused by intraplantar carrageenan or bone cancer lead to increases in phosphorylation of mTOR (p-mTOR) and S6K1 (p-S6K1) in rat spinal dorsal horn but not in 
DRGs $[88,89]$. In the chronic inflammatory pain and L5 spinal nerve ligation-induced neuropathic pain, western blot analysis showed significantly increased levels of p-mTOR and p-S6K1 [90]. These findings indicate that the impaired PI3K/Akt signal pathway contributes to diabetic neuropathy.

\section{PI3K/Akt Pathway and Spinal Cord Injury}

Chronic neuropathic pain and sensory abnormalities are common secondary consequences of spinal cord injury (SCI), affecting 60\% of patients with traumatic or ischemic injury [91-94]. SCI pain and associated dysesthesias manifest as at- and below-level neuropathic symptoms that are defined as either spontaneous(pain independent of peripheral stimuli) or evoked (occurring in responses to a noxious or non-noxious stimuli)[95]. It has been found that injury to the spinal cord results in enhanced intrinsic growth and hyper excitability of adjacent peripheral afferents that may contribute to the development of at-level pain syndromes[94, 96, 97].

Recent evidence shows that injury induced upregulation of chemical signals including NGF and Wnts leads to activation of PI3K and the subsequent inhibition of glycogen synthase kinase-3 $\beta$ (GSK-3 $\beta$ ) that may positively promote axonal elongation that contribute to the development of SCI pain[98-100]. In the excitotoxic SCI rats model using intraspinal quisqualic acid (QUIS), GSK-3 $\beta$ is inhibited by phosphorylation of the Sre-9 residue and directly promotes neurite outgrowth [101, 102]. Biochemical and immunohistochemical approaches shows a significantly increased level of GSK-3 $\beta$ expression [99]. In addition, QUIS animals treated with LY294002 revealed manifest reductions in neurite formation and elongation compared to the sham-vehicle animals[103]. To demonstrate if alterations in GSK-3 $\beta$ were evident early (3 days), and if application of a GSK-3 $\beta$ activator could reverse these spinal injury induced changes, LY294002 was intrathecally delivered once daily for 3 consecutive days starting on the day of surgery. Results show that short term administration GSK-3 $\beta$ activator (LY294002) prevents the development of at-level spontaneous dysesthesias and reduces DRG outgrowth[103]. Therefore, this indicates that PI3K can mediate the development of neuropathic pain after SCI.

\section{PI3K/Akt Pathway and Inflammatory Pain}

Tissue injury is normally associated with inflammation and inflammatory pain. Inflammatory pain is induced by inflammatory mediators released in injured tissue, such as prostaglandin E2, NGF, and bradykinin [104, 105]. It is also well documented that peripheral tissue inflammation or injury causes two changes in the nociceptive system, peripheral sensitization and central sensitization[106] Furthermore, enhanced synaptic transmission is considered to be essential for central sensitization after inflammatory stimuli [107]. Research demonstrates that PI3K is a key player in the establishment of central sensitization, the spinal cord phenomenon associated with persistent afferent inputs and contributes to chronic pain states in painful inflammatory conditions[41, 108]. Notably phosphorylation of the downstream kinase Akt at threonine 308 (pAkt-T) or at serine 473 (pAkt-S) is used as a marker of PI3K activation [109, 110]. In addition, PI3K regulates secondary messengers that activate various effectors such as Akt and ERK via the generation of PIP3[111]. These results led to the conclusion that PI3K signaling is involved in the modulation of nociceptive information, central sensitization, and synaptic plasticity in the central nervous system [41, 112]. In the inflammatory heat hyperalgesia rat model induced by intradermal injection of capsaicin and NGF, the levels of pAkt-T and pAkt-S significantly increased compared with sham group. 
LY294002, a PI3K inhibitor, blocked the increase in pAkt-T and pAkt-S levels in a dose-dependent manner [113]. Furthermore, when LY294002 or wortmannin is injected intradermally before the capsaicin injection, spontaneous pain behaviors, such as lifting and licking the affected paw, were suppressed in a dose-dependent manner. Several lines of evidence suggest an involvement of PI3Klinked cascades in the regulation of synaptic plasticity in CNS [114, 115]. Intraplantar injection of carrageenan produced a persistent thermal and tactile hyperpathia [116]. Our study found that spinal PI3K/Akt mediates pain behavior induced by plantar incision [13]. In addition to peripheral sensitization, evidence shows that spinal mechanisms also play a major role in this model $[117,118]$. It has been observed that wortmannin dose-dependently attenuated carrageenan-induced thermal and tactile hyperalgesia, and reversed an established thermal hyperalgesia when given as a posttreatment [89]. Moreover, LY294002 is reported to attenuate the phase I response which represents acute nociceptive processing [41].

\section{PI3K/Akt Pathway and Opioid Tolerance and hyperalgesia}

Despite a plethora of available potential treatment options for chronic pain, opioids are still the gold standard for its pharmacological management in the clinical setting. However, long-term use of these drugs is often limited due to the development of opioid tolerance or opioid-induced hyperalgesia( $\mathrm{OIH})$, characterized as progressive loss of analgesic potency after continuous morphine exposure that necessitates dose escalation to achieve equal pain relief [119-123]. $\mu$-opioid receptors (MOR) is a GPCR existing in the superficial dorsal horn of the spinal cord. As mentioned above, PI3K $\gamma$ can be regulated GPCR. Recent investigations have revealed that PI3K and Akt can be additional signaling mediators of MOR in sensory neurons. It was identified as a signaling pathway of MOR that involves PI3K $\gamma$, with subsequent stimulation of Akt and neuronal NOS (nNOS) [124]. Additional evidence for a prominent role of PI3K $\gamma$ in opioid signal transduction has been obtained, plus the essential function of PI $3 \mathrm{~K} \gamma$ in the development of long-term MOR desensitization and tolerance in the DRG [125]. Recent studies reveal that PI3K $\gamma$ is an essential element of pain- relieving opioid effects in neuronal cells [124, 125].

Glia, once thought to be merely supporting cells of the CNS, are now recognized to play a central role in the formation and maintenance of morphine tolerance[126]. It is suggested that morphineinduced migration of reactive microglia produce locally elevated concentrations of proinflammatory cytokines and chemokines[127]. Morphine-induced microglial migration is an $\mu$-opioid receptor and PI3K dependent [128]. It was reported that inhibiting PI3K reduces migration and ATP-induced Akt phosphorylation, implicating that the PI3K/Akt pathway in purinergic receptor mediated migration [129, 130]. The PI3K/Akt pathway have been demonstrated to be involved in ADPinduced microglial migration and chemo taxis by the P2Y12 receptor, which contribute to the development of pain [130].

The contribution of opioid-induced neuroinflammation is well documented [131] among the extensive studies regarding the mechanism underlying morphine tolerance. It is considered that morphine tolerance and neuropathic pain share common cellular mechanisms [132]. In a chronic morphine tolerance rat model, it was observed that Akt phosphorylation, cleaved Caspase-1dependent NALP1 inflammasome activation and IL-1 $\beta$ maturation in spinal cord neurons were significantly enhanced by morphine. This revealed the role of $\mu$-opioid/PI3K-Akt signaling/NALP1 inflammasome cascade in the development of morphine tolerance, and how treatment with LY294002 significantly reduced Caspase-1 cleavage, NALP1 inflammasome activation and 
attenuated morphine tolerance[133]. It is well known that repeated and long-term exposure to opioids causes opioid receptor-mediated adaptive changes within the nervous system, including desensitization, internalization, downregulation, and phosphorylation of opioid receptors [134] or heterodimerization with other receptors[135]. The findings demonstrated that the $\mu$ opioid receptortriggered $\mathrm{PI} 3 \mathrm{~K} / \mathrm{Akt} / \mathrm{mTOR}$ pathway in promoting morphine-induced spinal protein translation changes and is associated with morphine tolerance and hyperalgesia [136]. Besides, inhibition of the spinal PI3K/Akt not only reduces morphine-induced increase in p-mTOR, but also attenuates the development of morphine tolerance [136]. Thus the PI3K/Akt pathway is likely a novel target for preventing and/or treating chronic morphine tolerance and morphine-induced hyperalgesia.

\title{
Conclusion
}

By reviewing the current evidence, we discussed the role of PI3K/Akt pathway in chronic pain (Figure 1, 2, 3 and 4). These studies provided solid evidence that the PI3K/Akt pathway plays a pivotal role in the pathogenesis of bone cancer pain, neuropathic pain and inflammatory pain. Treatment with PI3K or the Akt inhibitor could attenuate mechanical allodynia and thermal hyperalgesia caused by pathological pain, implying that they may be beneficial and more effective therapeutic tools for chronic pain management. However, future extensive exploration should be performed with more selective and clinically relevant drugs targeting PI3K/Akt pathway.

\begin{abstract}
Abbreviations
BCP: bone cancer pain; PSL: partial sciatic nerve ligation; MCP-1: monocyte chemoattractant protein-1; CCR2: CC chemokine receptor-2; MAPK: mitogen-activated protein kinases; ERK: extracellular signal-related kinase; PI3K: phosphatidylinositol 3-kinase; TRPV1: transient receptor potential vanilloid subfamily member 1; TNF: tumor necrosis factor; NMDA receptor: N-methylD-aspartic acid receptor; PAR-2: proteinase-activated receptor-2; SP: substance P; NKIR: neurokinin-1 receptor; NGF: nerve growth factor; TrkA receptor: tropomyosin receptor kinase A receptor; PDK1: pyruvate dehydrogenase kinase 1; mTOR: mammalian target of rapamycin; PKC: protein kinase C; 4EBP: 4E-binding protein; ET-1: endothelin-1; ETA-R: endothelin type A receptor; MEK: methyl ethyl ketone; GSK3: glycogen synthase kinase 3; Smad1: drosophila mothers against decapentaplegic 1; NALP1: neutrophilic alkaline phosphatase 1
\end{abstract}

\section{Acknowledgements}

This work was supported by grants from National Natural Science Foundation of People's Republic China 81400917, 81371250, and 81571053, National Natural Science Foundation of Hubei Province 2014CFB449 and Specialized Research Fund for the Doctoral Program of Higher Education No.20130142120102, HUST No. 2014QT021.

\section{Conflicts of interest}

All authors have no conflicts of interest to disclose.

\section{Reference}

[1] Kuner R. Central mechanisms of pathological pain. Nat Med, 2010; 16: 1258-66.

[2] Zhou YQ, Gao HY, Guan XH, Yuan X, Fang GG, Chen Y, Ye DW. Chemokines and Their Receptors: Potential Therapeutic Targets for Bone Cancer Pain. Curr Pharm Des, 2015; 21: 5029-33. 
[3] Tian X, Wang G, Xu Y, Wang P, Chen S, Yang H, Gao F, Xu A, Cao F, Jin X, Manyande A, Tian Y. An improved tet-on system for gene expression in neurons delivered by a single lentiviral vector. Hum Gene Ther, 2009; 20: 113-23.

[4] Luo X, Wang X, Xia Z, Chung SK, Cheung CW. CXCL12/CXCR4 axis: an emerging neuromodulator in pathological pain. Rev Neurosci, 2016; 27: 83-92.

[5] Price TJ, Prescott SA. Inhibitory regulation of the pain gate and how its failure causes pathological pain. Pain, 2015; 156: 789-92.

[6] Ji RR, Kohno T, Moore KA, Woolf CJ. Central sensitization and LTP: do pain and memory share similar mechanisms? Trends Neurosci, 2003; 26: 696-705.

[7] Basbaum Al, Bautista DM, Scherrer G, Julius D. Cellular and molecular mechanisms of pain. Cell, 2009; 139: 267-84.

[8] Zhou YQ, Liu Z, Liu ZH, Chen SP, Li M, Shahveranov A, Ye DW, Tian YK. Interleukin-6: an emerging regulator of pathological pain. J Neuroinflammation, 2016; 13: 141.

[9] Sun Y, Ye DW, Zhang P, Wu YX, Wang BY, Peng G, Yu SY. Anti-rheumatic drug iguratimod (T614) alleviates cancer-induced bone destruction via down-regulating interleukin-6 production in a nuclear factor-kappaB-dependent manner. J Huazhong Univ Sci Technolog Med Sci, 2016; 36: 691-699.

[10] Li M, Mei W, Wang P, Yu Y, Qian W, Zhang ZG, Tian YK. Propofol reduces early post-operative pain after gynecological laparoscopy. Acta Anaesthesiol Scand, 2012; 56: 368-75.

[11] Castellino RC, Durden DL. Mechanisms of Disease: the PI3K-Akt-PTEN signaling node-an intercept point for the control of angiogenesis in brain tumors. Nature Clinical Practice Neurology, 2007; 3: 682-693.

[12] Endersby R, Baker SJ. PTEN signaling in brain: neuropathology and tumorigenesis. Oncogene, 2008; 27: 5416-5430.

[13] Xu B, Guan XH, Yu JX, Lv J, Zhang HX, Fu QC, Xiang HB, Bu HL, Shi D, Shu B, Qin LS, Manyande A, Tian YK. Activation of spinal phosphatidylinositol 3-kinase/protein kinase B mediates pain behavior induced by plantar incision in mice. Exp Neurol, 2014; 255: 71-82.

[14] Engelman JA, Luo J, Cantley LC. The evolution of phosphatidylinositol 3-kinases as regulators of growth and metabolism. Nat Rev Genet, 2006; 7: 606-19.

[15] Rommel C, Camps M, Ji H. PI3K delta and PI3K gamma: partners in crime in inflammation in rheumatoid arthritis and beyond? Nat Rev Immunol, 2007; 7: 191-201.

[16] Barrett D, Brown VI, Grupp SA, Teachey DT. Targeting the PI3K/AKT/mTOR signaling axis in children with hematologic malignancies. Paediatr Drugs, 2012; 14: 299-316.

[17] Ghigo A, Li M. Phosphoinositide 3-kinase: friend and foe in cardiovascular disease. Front Pharmacol, 2015; 6: 169.

[18] Stark AK, Sriskantharajah S, Hessel EM, Okkenhaug K. PI3K inhibitors in inflammation, autoimmunity and cancer. Curr Opin Pharmacol, 2015; 23: 82-91.

[19] Guillermet-Guibert J, Bjorklof K, Salpekar A, Gonella C, Ramadani F, Bilancio A, Meek S, Smith AJ, Okkenhaug K, Vanhaesebroeck B. The p110beta isoform of phosphoinositide 3-kinase signals downstream of $\mathrm{G}$ protein-coupled receptors and is functionally redundant with p110gamma. Proc Natl Acad Sci U S A, 2008; 105: 8292-7.

[20] Perino A, Ghigo A, Ferrero E, Morello F, Santulli G, Baillie GS, Damilano F, Dunlop AJ, Pawson C, Walser R, Levi R, Altruda F, Silengo L, Langeberg LK, Neubauer G, Heymans S, Lembo G, Wymann MP, Wetzker R, Houslay MD, laccarino G, Scott JD, Hirsch E. Integrating cardiac PIP3 
and cAMP signaling through a PKA anchoring function of p110gamma. Mol Cell, 2011; 42: 8495.

[21] Ferrandi C, Ardissone V, Ferro P, Ruckle T, Zaratin P, Ammannati E, Hauben E, Rommel C, Cirillo R. Phosphoinositide 3-Kinase Inhibition Plays a Crucial Role in Early Steps of Inflammation by Blocking Neutrophil Recruitment. Journal of Pharmacology and Experimental Therapeutics, 2007; 322: 923-930.

[22] Pezet S, McMahon SB. Neurotrophins: mediators and modulators of pain. Annu Rev Neurosci, 2006; 29: 507-38.

[23] Bogen O, Joseph EK, Chen X, Levine JD. GDNF hyperalgesia is mediated by PLCgamma, MAPK/ERK, PI3K, CDK5 and SrC family kinase signaling and dependent on the IB4-binding protein versican. Eur J Neurosci, 2008; 28: 12-9.

[24] Sun R-Q, Tu Y-J, Yan J-Y, Willis WD. Activation of protein kinase B/Akt signaling pathway contributes to mechanical hypersensitivity induced by capsaicin. Pain, 2006; 120: 86-96.

[25] Carvalho TT, Flauzino T, Otaguiri ES, Batistela AP, Zarpelon AC, Cunha TM, Ferreira SH, Cunha FQ, Verri WA. Granulocyte-Colony Stimulating Factor (G-CSF) induces mechanical hyperalgesia via spinal activation of MAP kinases and PI3K in mice. Pharmacology Biochemistry and Behavior, 2011; 98: 188-195.

[26] Guan XH, Lu XF, Zhang HX, Wu JR, Yuan Y, Bao Q, Ling DY, Cao JL. Phosphatidylinositol 3-kinase mediates pain behaviors induced by activation of peripheral ephrinBs/EphBs signaling in mice. Pharmacol Biochem Behav, 2010; 95: 315-24.

[27] Guan XH, Fu QC, Shi D, Bu HL, Song ZP, Xiong BR, Shu B, Xiang HB, Xu B, Manyande A, Cao F, Tian YK. Activation of spinal chemokine receptor CXCR3 mediates bone cancer pain through an Akt-ERK crosstalk pathway in rats. Exp Neurol, 2015; 263: 39-49.

[28] Mantyh PW. Bone cancer pain: from mechanism to therapy. Curr Opin Support Palliat Care, 2014; 8: 83-90.

[29] Song Z, Xiong B, Zheng H, Manyande A, Guan X, Cao F, Ren L, Zhou Y, Ye D, Tian Y. STAT1 as a downstream mediator of ERK signaling contributes to bone cancer pain by regulating MHC II expression in spinal microglia. Brain Behav Immun, 2016.

[30] Ke CB, He WS, Li CJ, Shi D, Gao F, Tian YK. Enhanced SCN7A/Nax expression contributes to bone cancer pain by increasing excitability of neurons in dorsal root ganglion. Neuroscience, 2012; 227: 80-9.

[31] Coleman RE. Clinical features of metastatic bone disease and risk of skeletal morbidity. Clin Cancer Res, 2006; 12: 6243s-6249s.

[32] Fu Q, Shi D, Zhou Y, Zheng H, Xiang H, Tian X, Gao F, Manyande A, Cao F, Tian Y, Ye D. MHC-I promotes apoptosis of GABAergic interneurons in the spinal dorsal horn and contributes to cancer induced bone pain. Exp Neurol, 2016; 286: 12-20.

[33] Ke C, Li C, Huang X, Cao F, Shi D, He W, Bu H, Gao F, Cai T, Hinton AO, Jr., Tian Y. Protocadherin 20 promotes excitatory synaptogenesis in dorsal horn and contributes to bone cancer pain. Neuropharmacology, 2013; 75: 181-90.

[34] Middlemiss T, Laird BJ, Fallon MT. Mechanisms of cancer-induced bone pain. Clin Oncol (R Coll Radiol), 2011; 23: 387-92.

[35] Song ZP, Xiong BR, Guan XH, Cao F, Manyande A, Zhou YQ, Zheng H, Tian YK. Minocycline attenuates bone cancer pain in rats by inhibiting NF-kappaB in spinal astrocytes. Acta Pharmacol Sin, 2016; 37: 753-62. 
[36] Ke C, Gao F, Tian X, Li C, Shi D, He W, Tian Y. Slit2/Robo1 Mediation of Synaptic Plasticity Contributes to Bone Cancer Pain. Mol Neurobiol, 2016.

[37] Guan X, Fu Q, Xiong B, Song Z, Shu B, Bu H, Xu B, Manyande A, Cao F, Tian Y. Activation of $\mathrm{PI}$ KKgamma/Akt pathway mediates bone cancer pain in rats. J Neurochem, 2015; 134: 590600.

[38] Zhou YQ, Liu Z, Liu HQ, Liu DQ, Chen SP, Ye DW, Tian YK. Targeting glia for bone cancer pain. Expert Opin Ther Targets, 2016: 1-10.

[39] Newton HB. Molecular neuro-oncology and development of targeted therapeutic strategies for brain tumors. Part 2: PI3K/Akt/PTEN, mTOR, SHH/PTCH and angiogenesis. Expert Rev Anticancer Ther, 2004; 4: 105-28.

[40] Gosselin RD, Varela C, Banisadr G, Mechighel P, Rostene W, Kitabgi P, Melik-Parsadaniantz S. Constitutive expression of CCR2 chemokine receptor and inhibition by MCP-1/CCL2 of GABAinduced currents in spinal cord neurones. J Neurochem, 2005; 95: 1023-34.

[41] Pezet S, Marchand F, D'Mello R, Grist J, Clark AK, Malcangio M, Dickenson AH, Williams RJ, McMahon SB. Phosphatidylinositol 3-kinase is a key mediator of central sensitization in painful inflammatory conditions. J Neurosci, 2008; 28: 4261-70.

[42] Choi Jl, Svensson Cl, Koehrn FJ, Bhuskute A, Sorkin LS. Peripheral inflammation induces tumor necrosis factor dependent AMPA receptor trafficking and Akt phosphorylation in spinal cord in addition to pain behavior. Pain, 2010; 149: 243-53.

[43] Huang W, Zhao Y, Zhu X, Cai Z, Wang S, Yao S, Qi Z, Xie P. Fluoxetine upregulates phosphorylated-AKT and phosphorylated-ERK1/2 proteins in neural stem cells: evidence for a crosstalk between AKT and ERK1/2 pathways. J Mol Neurosci, 2013; 49: 244-9.

[44] Hong SK, Jeong JH, Chan AM, Park JI. AKT upregulates B-Raf Ser445 phosphorylation and ERK1/2 activation in prostate cancer cells in response to androgen depletion. Exp Cell Res, 2013; 319: 1732-43.

[45] Bonnas C, Specht K, Spleiss O, Froehner S, Dietmann G, Kruger JM, Arbogast S, Feuerhake F. Effects of cold ischemia and inflammatory tumor microenvironment on detection of PI3K/AKT and MAPK pathway activation patterns in clinical cancer samples. Int J Cancer, 2012; 131: 1621-32.

[46] Jin D, Yang JP, Hu JH, Wang LN, Zuo JL. MCP-1 stimulates spinal microglia via PI3K/Akt pathway in bone cancer pain. Brain Res, 2015; 1599: 158-67.

[47] Liu S, Liu WT, Liu YP, Dong HL, Henkemeyer M, Xiong LZ, Song XJ. Blocking EphB1 receptor forward signaling in spinal cord relieves bone cancer pain and rescues analgesic effect of morphine treatment in rodents. Cancer Res, 2011; 71: 4392-402.

[48] Kawasaki Y, Kohno T, Zhuang ZY, Brenner GJ, Wang H, Van Der Meer C, Befort K, Woolf CJ, Ji RR. Ionotropic and metabotropic receptors, protein kinase A, protein kinase $C$, and SrC contribute to C-fiber-induced ERK activation and CAMP response element-binding protein phosphorylation in dorsal horn neurons, leading to central sensitization. J Neurosci, 2004; 24 : 8310-21.

[49] Steinle JJ, Meininger CJ, Chowdhury U, Wu G, Granger HJ. Role of ephrin B2 in human retinal endothelial cell proliferation and migration. Cell Signal, 2003; 15: 1011-7.

[50] Steinle JJ, Meininger CJ, Forough R, Wu G, Wu MH, Granger HJ. Eph B4 receptor signaling mediates endothelial cell migration and proliferation via the phosphatidylinositol 3-kinase pathway. J Biol Chem, 2002; 277: 43830-5. 
[51] Pereira PJS, Lazarotto LF, Leal PC, Lopes TG, Morrone FB, Campos MM. Inhibition of phosphatidylinositol-3 kinase $\gamma$ reduces pruriceptive, inflammatory, and nociceptive responses induced by trypsin in mice. Pain, 2011; 152: 2861-2869.

[52] Mizutani K, Roca H, Varsos Z, Pienta KJ. Possible mechanism of CCL2-induced Akt activation in prostate cancer cells. Anticancer Res, 2009; 29: 3109-13.

[53] Zhang J, Yu XH, Yan YG, Wang C, Wang WJ. PI3K/Akt signaling in osteosarcoma. Clin Chim Acta, 2015; 444: 182-92.

[54] Treede RD, Jensen TS, Campbell JN, Cruccu G, Dostrovsky JO, Griffin JW, Hansson P, Hughes R, Nurmikko T, Serra J. Neuropathic pain: redefinition and a grading system for clinical and research purposes. Neurology, 2008; 70: 1630-5.

[55] An K, Xu Y, Yang H, Shu HH, Xiang HB, Tian YK. Subarachnoid transplantation of immortalized galanin-overexpressing astrocytes attenuates chronic neuropathic pain. Eur J Pain, 2010; 14: 595-601.

[56] Xu Y, Tian XB, An K, Yang H, Tian YK. Lumbar transplantation of immortalized enkephalinexpressing astrocytes attenuates chronic neuropathic pain. Eur J Pain, 2008; 12: 525-33.

[57] Hains BC, Waxman SG. Activated microglia contribute to the maintenance of chronic pain after spinal cord injury. J Neurosci, 2006; 26: 4308-17.

[58] Sucena E, Delon I, Jones I, Payre F, Stern DL. Regulatory evolution of shavenbaby/ovo underlies multiple cases of morphological parallelism. Nature, 2003; 424: 935-8.

[59] Cordero-Erausquin M, Coull JA, Boudreau D, Rolland M, De Koninck Y. Differential maturation of GABA action and anion reversal potential in spinal lamina I neurons: impact of chloride extrusion capacity. J Neurosci, 2005; 25: 9613-23.

[60] Jutzeler CR, Huber E, Callaghan MF, Luechinger R, Curt A, Kramer JL, Freund P. Association of pain and CNS structural changes after spinal cord injury. Sci Rep, 2016; 6: 18534.

[61] Shi TJ, Huang P, Mulder J, Ceccatelli S, Hokfelt T. Expression of p-Akt in sensory neurons and spinal cord after peripheral nerve injury. Neurosignals, 2009; 17: 203-12.

[62] Wang GM, Tian XB, Chen JP, Yang SB, Gao F, Yang H, An K, Tian YK. Prevention of neuropathic pain in an animal model of spare nerve injury following oral immunization with recombinant adenovirus serotype 5-mediated NR2B gene transfer. Gene Ther, 2007; 14: 1681-7.

[63] Liang L, Fan L, Tao B, Yaster M, Tao YX. Protein kinase B/Akt is required for complete Freund's adjuvant-induced upregulation of Nav1.7 and Nav1.8 in primary sensory neurons. J Pain, 2013; 14: 638-47.

[64] Sun R, Yan J, Willis WD. Activation of protein kinase B/Akt in the periphery contributes to pain behavior induced by capsaicin in rats. Neuroscience, 2007; 144: 286-94.

[65] Tan AM, Chang YW, Zhao P, Hains BC, Waxman SG. Rac1-regulated dendritic spine remodeling contributes to neuropathic pain after peripheral nerve injury. Exp Neurol, 2011; 232: 222-33.

[66] Matsuda K, Orito K, Amagai Y, Jang H, Matsuda H, Tanaka A. Swing time ratio, a new parameter of gait disturbance, for the evaluation of the severity of neuropathic pain in a rat model of partial sciatic nerve ligation. J Pharmacol Toxicol Methods, 2015.

[67] Xu JT, Tu HY, Xin WJ, Liu XG, Zhang GH, Zhai CH. Activation of phosphatidylinositol 3-kinase and protein kinase $\mathrm{B} / \mathrm{Akt}$ in dorsal root ganglia and spinal cord contributes to the neuropathic pain induced by spinal nerve ligation in rats. Exp Neurol, 2007; 206: 269-79.

[68] Jin X, Gereau RWt. Acute p38-mediated modulation of tetrodotoxin-resistant sodium channels in mouse sensory neurons by tumor necrosis factor-alpha. J Neurosci, 2006; 26: 246-55. 
[69] Wilson-Gerwing TD, Dmyterko MV, Zochodne DW, Johnston JM, Verge VM. Neurotrophin-3 suppresses thermal hyperalgesia associated with neuropathic pain and attenuates transient receptor potential vanilloid receptor-1 expression in adult sensory neurons. J Neurosci, 2005; 25: 758-67.

[70] Lee JY, Jhun BS, Oh YT, Lee JH, Choe W, Baik HH, Ha J, Yoon KS, Kim SS, Kang I. Activation of adenosine $A 3$ receptor suppresses lipopolysaccharide-induced TNF-alpha production through inhibition of PI 3-kinase/Akt and NF-kappaB activation in murine BV2 microglial cells. Neurosci Lett, 2006; 396: 1-6.

[71] Marchetti L, Klein M, Schlett K, Pfizenmaier K, Eisel UL. Tumor necrosis factor (TNF)-mediated neuroprotection against glutamate-induced excitotoxicity is enhanced by N-methyl-Daspartate receptor activation. Essential role of a TNF receptor 2-mediated phosphatidylinositol 3-kinase-dependent NF-kappa B pathway. J Biol Chem, 2004; 279: 32869-81.

[72] Sommer C, Kress M. Recent findings on how proinflammatory cytokines cause pain: peripheral mechanisms in inflammatory and neuropathic hyperalgesia. Neurosci Lett, 2004; 361: 184-7.

[73] Chen YL, Law PY, Loh HH. Sustained activation of phosphatidylinositol 3-kinase/Akt/nuclear factor kappaB signaling mediates $\mathrm{G}$ protein-coupled delta-opioid receptor gene expression. J Biol Chem, 2006; 281: 3067-74.

[74] Pierchala BA, Ahrens RC, Paden AJ, Johnson EM, Jr. Nerve growth factor promotes the survival of sympathetic neurons through the cooperative function of the protein kinase $C$ and phosphatidylinositol 3-kinase pathways. J Biol Chem, 2004; 279: 27986-93.

[75] Ma W, Chabot JG, Quirion R. A role for adrenomedullin as a pain-related peptide in the rat. Proc Natl Acad Sci U S A, 2006; 103: 16027-32.

[76] Li D, Chen H, Luo XH, Sun Y, Xia W, Xiong YC. CX3CR1-Mediated Akt1 Activation Contributes to the Paclitaxel-Induced Painful Peripheral Neuropathy in Rats. Neurochem Res, 2016; 41: 130514.

[77] Albers JW, Pop-Busui R. Diabetic neuropathy: mechanisms, emerging treatments, and subtypes. Curr Neurol Neurosci Rep, 2014; 14: 473.

[78] Tesfaye S, Boulton AJ, Dickenson AH. Mechanisms and management of diabetic painful distal symmetrical polyneuropathy. Diabetes Care, 2013; 36: 2456-65.

[79] Faradji V, Sotelo J. Low serum levels of nerve growth factor in diabetic neuropathy. Acta Neurol Scand, 1990; 81: 402-6.

[80] Anand P, Terenghi G, Warner G, Kopelman P, Williams-Chestnut RE, Sinicropi DV. The role of endogenous nerve growth factor in human diabetic neuropathy. Nat Med, 1996; 2: 703-7.

[81] Lee PG, Hohman TC, Cai F, Regalia J, Helke CJ. Streptozotocin-induced diabetes causes metabolic changes and alterations in neurotrophin content and retrograde transport in the cervical vagus nerve. Exp Neurol, 2001; 170: 149-61.

[82] Hetman M, Kanning K, Cavanaugh JE, Xia Z. Neuroprotection by brain-derived neurotrophic factor is mediated by extracellular signal-regulated kinase and phosphatidylinositol 3-kinase. J Biol Chem, 1999; 274: 22569-80.

[83] Crowder RJ, Freeman RS. Phosphatidylinositol 3-kinase and Akt protein kinase are necessary and sufficient for the survival of nerve growth factor-dependent sympathetic neurons. J Neurosci, 1998; 18: 2933-43.

[84] Reynolds AJ, Bartlett SE, Hendry IA. Signalling events regulating the retrograde axonal transport of 125I-beta nerve growth factor in vivo. Brain Res, 1998; 798: 67-74. 
[85] Rondinone CM, Carvalho E, Wesslau C, Smith UP. Impaired glucose transport and protein kinase $B$ activation by insulin, but not okadaic acid, in adipocytes from subjects with Type II diabetes mellitus. Diabetologia, 1999; 42: 819-25.

[86] Cai F, Helke CJ. Abnormal PI3 kinase/Akt signal pathway in vagal afferent neurons and vagus nerve of streptozotocin-diabetic rats. Brain Res Mol Brain Res, 2003; 110: 234-44.

[87] Siddall PJ, McClelland JM, Rutkowski SB, Cousins MJ. A longitudinal study of the prevalence and characteristics of pain in the first 5 years following spinal cord injury. Pain, 2003; 103: 249257.

[88] Shih MH, Kao SC, Wang W, Yaster M, Tao YX. Spinal cord NMDA receptor-mediated activation of mammalian target of rapamycin is required for the development and maintenance of bone cancer-induced pain hypersensitivities in rats. J Pain, 2012; 13: 338-49.

[89] Xu Q, Fitzsimmons B, Steinauer J, O'Neill A, Newton AC, Hua XY, Yaksh TL. Spinal phosphinositide 3-kinase-Akt-mammalian target of rapamycin signaling cascades in inflammation-induced hyperalgesia. J Neurosci, 2011; 31: 2113-24.

[90] Liang L, Tao B, Fan L, Yaster M, Zhang Y, Tao YX. mTOR and its downstream pathway are activated in the dorsal root ganglion and spinal cord after peripheral inflammation, but not after nerve injury. Brain Res, 2013; 1513: 17-25.

[91] Finnerup NB, Johannesen IL, Sindrup SH, Bach FW, Jensen TS. Pain and dysesthesia in patients with spinal cord injury: A postal survey. Spinal Cord, 2001; 39: 256-62.

[92] Widerstrom-Noga E, Biering-Sorensen F, Bryce TN, Cardenas DD, Finnerup NB, Jensen MP, Richards JS, Siddall PJ. The International Spinal Cord Injury Pain Basic Data Set (version 2.0). Spinal Cord, 2014; 52: 282-6.

[93] Siddall PJ, Loeser JD. Pain following spinal cord injury. Spinal Cord, 2001; 39: 63-73.

[94] Bareiss SK, Gwaltney M, Hernandez K, Lee T, Brewer KL. Excitotoxic spinal cord injury induced dysesthesias are associated with enhanced intrinsic growth of sensory neurons. Neurosci Lett, 2013; 542: 113-7.

[95] Siddall PJ, Middleton JW. Spinal cord injury-induced pain: mechanisms and treatments. Pain Manag, 2015; 5: 493-507.

[96] Bedi SS, Yang Q, Crook RJ, Du J, Wu Z, Fishman HM, Grill RJ, Carlton SM, Walters ET. Chronic spontaneous activity generated in the somata of primary nociceptors is associated with painrelated behavior after spinal cord injury. J Neurosci, 2010; 30: 14870-82.

[97] Bedi SS, Lago MT, Masha LI, Crook RJ, Grill RJ, Walters ET. Spinal Cord Injury Triggers an Intrinsic Growth-Promoting State in Nociceptors. Journal of Neurotrauma, 2012; 29: 925-935.

[98] Zhou FQ, Zhou J, Dedhar S, Wu YH, Snider WD. NGF-induced axon growth is mediated by localized inactivation of GSK-3beta and functions of the microtubule plus end binding protein APC. Neuron, 2004; 42: 897-912.

[99] Saijilafu, Hur EM, Liu CM, Jiao Z, Xu WL, Zhou FQ. PI3K-GSK3 signalling regulates mammalian axon regeneration by inducing the expression of Smad1. Nat Commun, 2013; 4: 2690.

[100] Hollis ER, 2nd, Zou Y. Expression of the Wnt signaling system in central nervous system axon guidance and regeneration. Front Mol Neurosci, 2012; 5: 5.

[101] Hur EM, Saijilafu, Lee BD, Kim SJ, Xu WL, Zhou FQ. GSK3 controls axon growth via CLASPmediated regulation of growth cone microtubules. Genes Dev, 2011; 25: 1968-81.

[102] Bareiss S, Kim K, Lu Q. $\delta$-Catenin/NPRAP: A new member of the glycogen synthase kinase-3 $\beta$ signaling complex that promotes $\beta$-catenin turnover in neurons. Journal of Neuroscience 
Research, 2010: n/a-n/a.

[103] Bareiss SK, Dugan E, Brewer KL. PI3K mediated activation of GSK-3beta reduces at-level primary afferent growth responses associated with excitotoxic spinal cord injury dysesthesias. Mol Pain, 2015; 11: 35.

[104] Julius D, Basbaum AI. Molecular mechanisms of nociception. Nature, 2001; 413: 203-10.

[105] Woolf CJ, Salter MW. Neuronal plasticity: increasing the gain in pain. Science, 2000; 288: 17659.

[106] Treede RD, Meyer RA, Raja SN, Campbell JN. Peripheral and central mechanisms of cutaneous hyperalgesia. Prog Neurobiol, 1992; 38: 397-421.

[107] Latremoliere A, Woolf CJ. Central sensitization: a generator of pain hypersensitivity by central neural plasticity. J Pain, 2009; 10: 895-926.

[108] Leinders M, Koehrn FJ, Bartok B, Boyle DL, Shubayev V, Kalcheva I, Yu N-K, Park J, Kaang B-K, Hefferan MP, Firestein GS, Sorkin LS. Differential distribution of PI3K isoforms in spinal cord and dorsal root ganglia: Potential roles in acute inflammatory pain. Pain, 2014; 155: 1150-1160.

[109] Kuruvilla R, Ye H, Ginty DD. Spatially and functionally distinct roles of the PI3-K effector pathway during NGF signaling in sympathetic neurons. Neuron, 2000; 27: 499-512.

[110] Lin CH, Yeh SH, Lin CH, Lu KT, Leu TH, Chang WC, Gean PW. A role for the PI-3 kinase signaling pathway in fear conditioning and synaptic plasticity in the amygdala. Neuron, 2001; 31: 84151.

[111] Pearce LR, Komander D, Alessi DR. The nuts and bolts of AGC protein kinases. Nat Rev Mol Cell Biol, 2010; 11: 9-22.

[112] Hoeffer CA, Klann E. mTOR signaling: at the crossroads of plasticity, memory and disease. Trends Neurosci, 2010; 33: 67-75.

[113] Zhuang ZY, Xu H, Clapham DE, Ji RR. Phosphatidylinositol 3-kinase activates ERK in primary sensory neurons and mediates inflammatory heat hyperalgesia through TRPV1 sensitization. J Neurosci, 2004; 24: 8300-9.

[114] Hou L, Klann E. Activation of the phosphoinositide 3-kinase-Akt-mammalian target of rapamycin signaling pathway is required for metabotropic glutamate receptor-dependent long-term depression. J Neurosci, 2004; 24: 6352-61.

[115] Jaworski J, Sheng M. The growing role of mTOR in neuronal development and plasticity. Mol Neurobiol, 2006; 34: 205-19.

[116] Pritchard RA, Falk L, Larsson M, Leinders M, Sorkin LS. Different phosphoinositide 3-kinase isoforms mediate carrageenan nociception and inflammation. Pain, 2016; 157: 137-46.

[117] Neugebauer V, Schaible HG. Evidence for a central component in the sensitization of spinal neurons with joint input during development of acute arthritis in cat's knee. J Neurophysiol, 1990; 64: 299-311.

[118] Bird GC, Han JS, Fu Y, Adwanikar H, Willis WD, Neugebauer V. Pain-related synaptic plasticity in spinal dorsal horn neurons: role of CGRP. Mol Pain, 2006; 2: 31.

[119] Chan BK, Tam LK, Wat CY, Chung YF, Tsui SL, Cheung CW. Opioids in chronic non-cancer pain. Expert Opin Pharmacother, 2011; 12: 705-20.

[120] Bekhit MH. Opioid-induced hyperalgesia and tolerance. Am J Ther, 2010; 17: 498-510.

[121] Guo G, Peng Y, Xiong B, Liu D, Bu H, Tian X, Yang H, Wu Z, Cao F, Gao F. Involvement of chemokine CXCL11 in the development of morphine tolerance in rats with cancer-induced bone pain. J Neurochem, 2016. 
[122] Cao F, Chen SS, Yan XF, Xiao XP, Liu XJ, Yang SB, Xu AJ, Gao F, Yang H, Chen ZJ, Tian YK. Evaluation of side effects through selective ablation of the mu opioid receptor expressing descending nociceptive facilitatory neurons in the rostral ventromedial medulla with dermorphin-saporin. Neurotoxicology, 2009; 30: 1096-106.

[123] Ye D, Bu H, Guo G, Shu B, Wang W, Guan X, Yang H, Tian X, Xiang H, Gao F. Activation of CXCL10/CXCR3 signaling attenuates morphine analgesia: involvement of Gi protein. J Mol Neurosci, 2014; 53: 571-9.

[124] Cunha TM, Roman-Campos D, Lotufo CM, Duarte HL, Souza GR, Verri WA, Jr., Funez MI, Dias QM, Schivo IR, Domingues AC, Sachs D, Chiavegatto S, Teixeira MM, Hothersall JS, Cruz JS, Cunha FQ, Ferreira SH. Morphine peripheral analgesia depends on activation of the PI3Kgamma/AKT/nNOS/NO/KATP signaling pathway. Proc Natl Acad Sci U S A, 2010; 107: 4442-7.

[125] Konig C, Gavrilova-Ruch O, von Banchet GS, Bauer R, Grun M, Hirsch E, Rubio I, Schulz S, Heinemann SH, Schaible HG, Wetzker R. Modulation of mu opioid receptor desensitization in peripheral sensory neurons by phosphoinositide 3-kinase gamma. Neuroscience, 2010; 169: 449-54.

[126] Song $P$, Zhao ZQ. The involvement of glial cells in the development of morphine tolerance. Neurosci Res, 2001; 39: 281-6.

[127] Cao F, Gao F, Xu AJ, Chen ZJ, Chen SS, Yang H, Yu HH, Mei W, Liu XJ, Xiao XP, Yang SB, Tian XB, Wang XR, Tian YK. Regulation of spinal neuroimmune responses by prolonged morphine treatment in a rat model of cancer induced bone pain. Brain Res, 2010; 1326: 162-73.

[128] Horvath RJ, DeLeo JA. Morphine enhances microglial migration through modulation of P2X4 receptor signaling. J Neurosci, 2009; 29: 998-1005.

[129] Ohsawa K, Irino Y, Nakamura Y, Akazawa C, Inoue K, Kohsaka S. Involvement of P2X4 and P2Y12 receptors in ATP-induced microglial chemotaxis. Glia, 2007; 55: 604-16.

[130] Irino Y, Nakamura Y, Inoue K, Kohsaka S, Ohsawa K. Akt activation is involved in P2Y12 receptor-mediated chemotaxis of microglia. J Neurosci Res, 2008; 86: 1511-9.

[131] Wang X, Loram LC, Ramos K, de Jesus AJ, Thomas J, Cheng K, Reddy A, Somogyi AA, Hutchinson MR, Watkins LR, Yin $H$. Morphine activates neuroinflammation in a manner parallel to endotoxin. Proc Natl Acad Sci U S A, 2012; 109: 6325-30.

[132] Mayer DJ, Mao J, Holt J, Price DD. Cellular mechanisms of neuropathic pain, morphine tolerance, and their interactions. Proc Natl Acad Sci U S A, 1999; 96: 7731-6.

[133] Tian Y, Liu M, Mao-Ying QL, Liu H, Wang ZF, Zhang MT, Wang J, Li Q, Liu SB, Mi WL, Ma HJ, Wu GC, Wang YQ. Early single Aspirin-triggered Lipoxin blocked morphine anti-nociception tolerance through inhibiting NALP1 inflammasome: Involvement of PI3k/Akt signaling pathway. Brain Behav Immun, 2015; 50: 63-77.

[134] Ueda H, Ueda M. Mechanisms underlying morphine analgesic tolerance and dependence. Front Biosci (Landmark Ed), 2009; 14: 5260-72.

[135] Szabo I, Chen XH, Xin L, Adler MW, Howard OM, Oppenheim JJ, Rogers TJ. Heterologous desensitization of opioid receptors by chemokines inhibits chemotaxis and enhances the perception of pain. Proc Natl Acad Sci U S A, 2002; 99: 10276-81.

[136] Xu JT, Zhao JY, Zhao X, Ligons D, Tiwari V, Atianjoh FE, Lee CY, Liang L, Zang W, Njoku D, Raja SN, Yaster M, Tao YX. Opioid receptor-triggered spinal mTORC1 activation contributes to morphine tolerance and hyperalgesia. J Clin Invest, 2014; 124: 592-603. 


\section{Figure legends}

Figure 1. Schematic illustration of potential mechanisms of PI3K/Akt pathway in the processing of bone cancer pain. MCP-1: monocyte chemoattractant protein-1; CCR2: CC chemokine receptor-2; MAPK: mitogen-activated protein kinases; ERK: extracellular signal-related kinase; PI3K: phosphatidylinositol 3-kinase; PKB/Akt: protein kinase B; TRPV1: transient receptor potential vanilloid subfamily member 1 ;

Figure 2. Schematic illustration of potential mechanisms of PI3K/Akt pathway in the processing of neuropathic pain. ET-1: endothelin-1; ETA-R: endothelin type A receptor; MAPK: mitogen-activated protein kinases; ERK: extracellular signal-related kinase; PI3K: phosphatidylinositol 3-kinase; PKB/Akt: protein kinase B; MEK: mitogen-activated ERKregulating kinase; GSK3: glycogen synthase kinase 3; Smad1: drosophila mothers against decapentaplegic 1 .

Figure 3. Schematic illustration of potential mechanisms of PI3K/Akt pathway in the processing of inflammatory pain. TNF: tumor necrosis factor; NMDA receptor: N-methyl-Daspartic acid receptor; PAR-2: proteinase-activated receptor-2; SP: substance P; NKIR: neurokinin1 receptor; NGF: nerve growth factor; TrkA receptor: tropomyosin receptor kinase A receptor; PI3K phosphatidylinositol 3-kinase; ERK: extracellular signal-related kinase; PKB/Akt: protein kinase B; PDK1: pyruvate dehydrogenase kinase 1; mTOR: mammalian target of rapamycin; PKC: protein kinase C; 4EBP: 4E-binding protein.

Figure 4. Schematic illustration of potential mechanisms of PI3K/Akt pathway in the processing of morphine tolerance. $\mathrm{PI} 3 \mathrm{~K}$ : phosphatidylinositol 3-kinase; PKB/Akt: protein kinase B; mTOR: mammalian target of rapamycin; NALP1: neutrophilic alkaline phosphatase 1 .

SA 